\title{
9. Sensing the air and experimenting with environmental citizenship
}

\author{
Jennifer Gabrys
}

\begin{abstract}
This chapter analyzes community-led citizen sensing projects as a new form of environmental citizenship. Sensing and monitoring air quality can be playful forms of civic engagement with public issues. In these site-specific citizen sensing projects, creative means are being used to engage citizens in measuring air pollution with the aid of technology. The chapter argues that such experimental initiatives should be approached as material processes in which new forms of data retrieval and democratic engagement are developed that can potentially give rise to new and more just power relations in knowledge production.
\end{abstract}

Keywords: Environmental citizenship, citizen sensing, data, air quality, citizen science

If you should find yourself standing outside the Hobgoblin Pub on New Cross Road in the Borough of Lewisham, London, you might notice a grayish-white box approximately two-and-a-half meters high scrawled with a faded and cascading line of graffiti. Wedged in a space between the buildings and facing out toward the road, the air vent and monitoring equipment at the top of this structure may be one of the few details that betray the purpose of this object, which is to measure air quality at this fixed spot in London. One of the stations in the London Air Quality Network (LAQN) that covers 33 boroughs, this monitoring station contributes to the hourly indexes of air quality and news of episodes of high pollution risk in London. Detecting sulfur dioxide $\left(\mathrm{SO}_{2}\right)$, particulate matter 10 and 2.5 ( $\left.\mathrm{PM} \mathrm{10}, \mathrm{PM} 2.5\right)$, as well as nitrogen oxide $(\mathrm{NO})$ and nitrogen dioxide $\left(\mathrm{NO}_{2}\right)$, the station generates data that indicate whether the UK is meeting EU air quality objectives for

Glas, R., S. Lammes, M. de Lange, J. Raessens, and I. de Vries, eds. 2019. The Playful Citizen. Civic Engagement in a Mediatized Culture. Amsterdam: Amsterdam University Press. DOI: $10.5117 / 9789462984523 / \mathrm{CHO} 9$ 
both the short- and long-term emission of pollutants. The data also inform environmental science research and are managed and made available by the Environmental Research Group (ERG) at King's College London where this network is managed and run (London Air Quality Network n.d.).

Passersby may experience in a potentially fleeting way the connection between this station, the local air quality, and the data it generates, which typically circulate in spaces of environmental science and policy. The data that is generated at this fixed site could be seen to be black-boxed, and located in spaces somewhat remote from everyday experiences of air quality on the street. In order to bring air pollution data gathered at this station and the approximately 100 other stations in the LAQN, ERG have designed a 'London Air App' to allow people to observe emissions levels at key monitoring sites, and to make inferences about their own personal exposure when passing through these sites. While this strategy makes the data of fixed sites more accessible through an air quality app, the modes of pollution that individuals experience in their everyday trajectories may be quite different than the types of pollution that are captured through fixed monitoring sites generating data that is averaged over set monitoring periods. For instance, the fixed point at the New Cross Road station typically records an annual exceedance of $\mathrm{NO}_{2}$, which is a pollutant formed in the combustion of fuel and is largely the result of high levels of automobile use in the city. In fact, this site exceeds the EU air quality objectives which is no more than $40 \mu \mathrm{m} / \mathrm{m}^{3}$ of $\mathrm{NO}_{2}$ per year. Yet, all along New Cross Road individual moments and locations of exposure may generate a far different set of 'pollution episodes,' with different consequences for urban dwellers in these areas.

Inevitably, the question emerges of how individuals may map their own exposure to air pollution, which is likely to differ from the sites of the official monitoring stations. One response that attempts to monitor air quality beyond fixed sites includes community deployments of diffusion tubes which are a low-cost analog method for gauging air pollution, but require many week-long deployments of tubes that are then sent off to labs for analysis and data production. In this case, the process of gathering air pollution data may be more egalitarian, but the generation and analysis of meaningful data is something that takes place in a remote laboratory setting. Beyond this approach, environmental monitoring is now proliferating from a project undertaken by environmental scientists and governmental agencies to a practice in which DIY groups and creative practitioners are engaged, often as a form of citizen or grassroots science. Many of these monitoring projects might be called 'citizen sensing,' since they typically deploy smart phones 
and portable sensors with the intention of democratizing the collection and use of sensor data. The general ethos of these projects is that by enabling the monitoring of local environments, it may also be possible to achieve increased engagement with environmental concerns.

One primary way such citizen-sensing projects have sprung up is through direct engagement with sites of contamination or pollution. Air, noise, and water pollution are local environmental disturbances, even if distributed, that most urban dwellers experience on a regular basis. Yet, even then, some urban residents experience more than others since sites of pollution are often concentrated in lower-income urban areas. Citizen sensing of pollution is a strategy that attempts to bring pollution data from the spaces of expert and governmental oversight to an experience that is available to citizens equipped with mobile phones and portable sensors. A proliferation of creative practice, creative computing, and DIY projects have emerged in the area of sensing environmental pollution. Some citizen-sensing projects use the itinerant aspects of individual exposure to air pollution as a site for unique and mobile monitoring experiments, which cannot be compared to fixed sites of detection. For example, Preemptive Media's Area's Immediate Reading consists of a mobile and individual air monitoring device for gauging individual exposure to air pollutants (Preemptive Media 2006). Other projects suggest that by focusing on environmental disturbances new questions about the health of individual bodies in relation to environmental health can emerge. For instance, Natalie Jeremijenko's Environmental Health Clinic tests pollutants in river water samples to raise discussions about individual health and exposure to environmental pollutants (Jeremijenko n.d.-a). Whether displaying pollution levels or developing platforms to make pollution information more accessible to help facilitate sound decision making, the majority of citizen-sensing pollution projects attempt to make the details of environmental pollution more immediate and actionable.

These projects test, experiment with, and mobilize alternative modes of environmental citizenship in order to address environmental concerns. Yet, in what ways do practices of environmental monitoring with sensing devices give rise not just to experimental modes of participation and civic engagement, but also to different modalities for experiencing environmental pollution? ${ }^{1}$ Within these projects, how does the experience and

1 This discussion on the experience and experiment of sensing air pollution draws and builds on my previous work on environmental sensors, which I develop in the context of Isabelle Stengers' analysis of the shared (French) etymology of experiment and experience (in relation to Whitehead). See Whitehead 1929; Stengers 2008; Gabrys 2012. 
experiment of air pollution become a site of political as well as potentially playful engagement? In this chapter, I consider how creative practices that sense air pollution, also experiment with the tactics and arrangements of environmental citizenship in order to open up the possibility for new experiences, engagements, and political encounters with environmental matters of concern. These experiments and experiences, however, are not just a matter of enabling citizens to use technology to act on their environments. Rather, as I suggest here and in the larger Citizen Sense project that this work draws from, computational sensing technologies are bound up with the generation of new relations, entities, occasions, and interpretive registers of sensing. Sensor-based engagements with environments do not simply detect external phenomena to be reported, rather they bring together experiencing entities to make possible new arrangements of environmental sensing and data.

While citizen-sensing practices attempt to generate new modes of civic and actionable environmental data, at the same time I consider in what ways it might be possible to develop an analysis of these environmental practices that does not necessarily fix them as objects of study, but rather creates generative approaches by considering the data practices that emerge through these projects, which might further spur new experiments with additional data practices. With an examination of citizen-sensing projects that develop experimental and creative approaches to monitoring air quality, including Feral Robotic Dogs, Pigeon Blog, and Air Quality Egg, I consider how these technological modes of sensing generate distinct practices of environmental citizenship in and through engagement with data.

While these environmental sensing projects are ostensibly focused on creating opportunities for citizen scientists (of sorts) to generate their own data, these projects also create additional data in and around the practices they set in motion. This is another way of saying that rather than consider environmental citizenship as something that inheres within a particular subject position, I am instead interested in considering how practices distributed across human and more-than-human registers might emerge through distinct performances or enactments of environmental citizenship. Environmental citizenship is by no means a new concept, and has been discussed at length across a range of literatures too vast to summarize here. But I take as a cue, from Rebecca Ellis and Claire Waterton, the notion of "environmental citizenship in the making" (Ellis and Waterton 2004), or as I would further suggest, a processual and relational approach to environmental citizenship based on Whitehead's conception of citizenship (Whitehead 1929), as a way to think through the emergent practices of 
monitoring and sensing urban air quality as a distinct performance and articulation of environmental citizenship (Gabrys 2013).

In considering the types of practices that emerge, I examine environmental citizenship as a distributed process rather than as something that is situated at the site of a fixed human subject. Distributed and more-thanhuman modes of participation contribute to air pollution and its monitoring. From computational sensors to moving air masses, manufacturing and transport, vegetation and animal bodies, temperature gradients and topography, economic inequality and real estate, as well as policy and modeling, a number of factors converge in the project of experiencing and experimenting with sensing air pollution. Which of these processual entities are more or less evident in monitoring the air? What does the air (and 'the environment') become through monitoring devices, and what are its materializations and experiences? What are the relationships, political engagements, and ways of mobilizing data that make for the most a/effective environmental practices? And if monitoring and citizen sensing are emerging as new modes of environmental participation, in what ways do these experiments further enable practices for engaging with and addressing air pollution, and for speculating with environmental objects and environmental politics?

\section{Citizen science, citizen sensing, and doing science differently}

The current range of citizen-sensing projects can be perceived to draw on a longer history of environmental practice in the form of citizen science. Amateurs' monitoring of their environment, for instance, have in the past contributed to the emergence of natural history, while more contemporary attempts have informed the rise of popular environmentalist movements and the public's current engagement in environmental matters of scientific and political controversy. Science and technology studies (STS) focused on citizen science-environmental and otherwise-have, in many cases, analyzed how public engagement with science is variously organized to influence the ways in which the public can be constituted as entities able to participate in environmental politics (Irwin and Michael 2003). Amateur natural histories, biodiversity monitoring projects and toxic waste events have been among the citizen-science and public engagements studied by STS researchers (Wynne 1996). In these studies, citizen science and public engagement with science emerge not as easy fixes to making science more 
democratic, but rather as particular expressions of environmental politics, citizenship, and matters of concern.

Citizen science — and sensing — can be seen as both an augmentation to science, as well as an expanded way of practicing science in relation to pedagogical and political aims (Jasanoff 2003). Many current scientific initiatives suggest that the observation and monitoring of earth processes remains one of the core areas for advancing scientific understanding of environmental change. At the same time, environmental monitoring projects often seek to find ways to broaden the scope of environmental observation beyond the sciences exclusively, and to make ecological observation more accessible and engaging to a diverse range of participants. The process of gathering and making these observations more participatory is often seen as a way to overcome the relative crisis of environmental engagement in political and cultural spheres: by making environmental change more evident and distributed across sensing subjects, environmental action may also be facilitated.

There is extensive literature discussing citizen engagement in monitoring air pollution, although often at the level of how the public responds to or engages with scientific findings, and not as practitioners of science themselves (e.g. Bickerstaff and Walker 2003; Whitehead 2009). Yet, at the same time, analyses of participatory and environmental-justice-focused engagement with air pollution have discussed the many and even noncomputational ways in which air samples may be collected in order to inform environmental science and politics. The Louisiana Bucket Brigade is an environmental activist group that Gwen Ottinger discusses as engaging in a DIY-bucket collection method of monitoring air quality in a neighborhood adjacent to oil and gas refineries located in a region referred to as "Cancer Alley" in a part of the United States with particularly high rates of cancer (Ottinger 2010). While the bucket becomes a device for collecting air samples in a more democratic and local way, the analysis of the air samples must still take place in laboratories (similar to the diffusion tube air analysis) that are not sites of citizen engagement. The project presents a low-tech way of conducting a version of citizen science, which is largely focused on environmental activism and justice.

From citizen science to participatory sensing, crowd-sourcing, civic science, DIY media, and citizen sensing, a number of terms have emerged to describe these widespread practices of environmental monitoring and data gathering that work in various ways to democratize technoscientific tools and our understanding of the environment. While these terms are used in different ways to stress the scientific, big data, or civic aspects 
of these practices, in this chapter I work with the term citizen sensing in order to draw explicit attention to the ways in which computational and mobile practices of environmental monitoring might be discussed as modes of citizen sensing, specifically. Citizen-science projects, I suggest, are increasingly transforming into citizen-sensing projects, where digital devices equipped with sensors are used to monitor environments and gather data.

Practices of monitoring and sensing environments that were once the focus of scientific disciplines have migrated to a number of everyday participatory applications, where users of smart phones and networked devices are able to track, study, and report on their environments. Citizen sensing, as I am defining the practice here, encompasses or refers to those sensing activities that often use computational sensing technologies in the form of smart phones, mobile and low-cost electronic devices such as Arduino, Nanode and Raspberry Pi, and platforms to report and potentially act on environmental events. ${ }^{2}$ Such distribution of sensing capabilities across sensor networks and multiple mobile and individualized platforms, have arguably become a focused site for environmental and technological engagement. Citizen-sensing projects are closely related to citizen-science studies, but differ in how they seek to enable environmental practice through direct engagement with environmental monitoring technologies, rather than as necessarily filtered through engagement with experts. The citizen-sensing applications that strongly resemble citizen science projects most often are based on similar practices of individuals voluntarily tracking and monitoring environmental data related to everything from pollution to biodiversity counts. Citizen-sensing practices have been described at times as making inventive contributions to both the research and development of technological tools and to the varing methods of environmental monitoring (Burke et al. 2006). These practices range from undertakings that address the ways in which microsensor data may complement other environmental observations, including remote sensing in order to provide more complete pictures of environmental issues, as well as ubiquitous-computing approaches that often focus on the capacities and practices of sensor technologies. These

2 The most commonly referenced platform for environmental data is one that has been in continual transformation. First taking the form of Pachube, as developed by Usman Haque, this platform was subsequently developed as a quasi-open yet commercially based structure in the form of Cosm, as has now become a more commercial and subscription-led platform rebranded as Xively. The development and migration of this platform from an open community to a commercial enterprise is a topic that could be researched and analyzed at length. However there is no room in this paper to deal with this parallel development in how environmental sense data may actually be aggregated, presented, and made accessible in an online format. 
practices can also include social or civic media projects that emphasize the ways in which social networking can mobilize collected data in new ways to effect policy and mobilization.

Sometimes mobile sensor technologies have enabled more thorough practices of environmental monitoring and observation than those already being conducted by citizen-science initiatives, as in counting and tagging biological activities. In other cases, the capacities of mobile sensor technologies have enabled more distributed and potentially more accurate collection of data, such as urban air or noise pollution. Some applications extend the scope of citizen sensing to encompass not just microsensor data and the use of smart phones, but also draw on remote sensing and mapping to enable the tracking of deforestation or animal movements. In still other instances, these mobile sensor applications have enabled new forms of democratic organization and communication about environmental issues by effectively crowd-sourcing environmental observations in order to inform environmental policy and action. What emerges in this diverse set of practices that are in many ways connected to citizen science is a set of proposals for democratizing environmental engagement and developing other ways of doing environmental science and politics.

Many of the claims for citizen sensing are arguably still in the realm of proposals and experiments, where the hope is that distributed capacities of computational sensors will enable increased civic engagement with environmental issues. But in what ways do citizen-sensing engagements influence the modes of environmental participation that emerge? And what does it mean to 'sense' or experience air pollution with computational sensors? While the impacts of air pollution on human health are one of the key motivators for establishing quality standards, often the means of monitoring and enforcing these standards misses the more localized pollution experienced by people who actually live in urban areas affected by these events. Environmental health and individual health are bound up in articulations of what does and does not count as a 'pollution episode.' Strategies for monitoring pollution at the citizen or individual level are seen as a way to counter or redress the possible gaps in data, but there is more to these projects than this, since in mobilizing sensors to bring environmental monitoring into a more democratic set of engagements new material-political actors, engagements, and experiments emerge—along with new political possibilities and controversies.

Sensing technologies are entangled with and mobilize new environmental monitoring practices and new ways of gathering data. But, the 
other more primary reason for engaging with these practices as citizen sensing practices, is to draw out the ways in which computational devices are at once sensing and actuating technologies, as well as modes for sensing and experiencing environments. In this sense, citizen science and citizen sensing may have similar objectives in observing and monitoring environments, but they unfold through very different material entanglements and relationalities, ways of practicing and generating data, and in their articulation of what counts as environmental politics. The modes of engagement and spaces through which data is gathered, analyzed, and communicated are key aspects to the emergence of these environmental modes of practice. Citizen-sensing projects are frequently described as data campaigns, or as identifying an issue about which more data may be needed in order to effect policy changes. As numerous STS researchers have noted, however, data are always embedded within political practices, structures and institutions that inform everything from how data are delineated and collected, to how they are joined up, communicated and acted upon (e.g. Bowker 2005). It is these practices of data gathering as characteristic of environmental monitoring and engagement that I will focus on for the remainder of this chapter by looking at three projects that engage specifically with computational modes of sensing environments in order to gather data and inform environmental action. I am interested in finding out what relations, practices, and political possibilities emerge from these distinct mobilizations of environmental data.

\section{Dogs, pigeons, and eggs: Creaturing data}

In many ways, pollution monitoring has been a key initiator for creative practice and creative computing projects engaged in gathering environmental data. Area's Immediate Reading, Pigeon Blog, Common Sense, Street Sweepers, Feral Robotic Dogs, Air Quality Egg, and others, are various scientific and environmental monitoring projects that have different actors, arrangements, tools, and spaces where the readings are conducted. At the same time, in pollution monitoring projects, the gathering of sense data is often closely tied to affecting and effecting political action and environmental change, by addressing how data is collected, generated, and acted upon. Yet, in each of these projects environmental sense data emerges not as a universal category or form, but as a concrete entity that is a part of the process of participating in environments. "The actual world is a process," as Whitehead writes, and this "process is the becoming of actual entities. 
Thus actual entities are creatures; they are also termed 'actual occasions'" $(1929,22)$. Actual occasions are living creatures, or lively meetings of entities that concretize routes in and through events. In this sense, the gathering of data might be identified as more than a static fact that documents air quality at any given time or place, and instead be approached as a practice that gives rise to particular entities that further generate concrete worlds. These entities are "creatures" that form and are formed by processes-here through practices of gathering environmental data.

Working with this Whitehead-inspired analysis of how the specific entities of environmental data emerge through sensing, I suggest that environmental sensing projects are creaturing processes, where the entities that emerge are continuous with specific situations and modalities of participation. The projects I discuss below engage in the creaturing of data in a double sense, however, since they also deploy more-than-human participants, including robotic dogs, homing pigeons, and plastic eggs, as concrete entities for drawing together citizen-sensing practices. Data, in this sense, are not an abstract store of information or something to be coherently visualized, but rather are bound up with the making of actual occasions and material processes. Data may typically appear to be the primary objective of environmental sensing projects, which focus on obtaining data in order to influence environmental policy and practices, but along the way the relations and material arrangements that data gathering sets in place begin to creature (and in the process, materialize) new entities and societies of objects that emerge through these practices. By turning to the creaturing and materializing of data, I consider in the projects that follow how data mobilize or underwrite environmental practices, while at the same time often failing to materialize in the ways anticipated which generates participatory arrangements that are different than those intended. The failure of environmental sense data to perform as an easy spur to environmental action, it turns out, can even be a key way in which the creaturely aspects of data emerge. Data unfold less through instrumental or even epistemic registers, arguably, and more as affective and materialized attractors for experimenting with environmental citizenship.

\section{Dogs}

One of the earliest creative practice projects to engage with environmental sensing, Feral Robotic Dogs, was originally developed by Natalie Jeremijenko in 2002 and advanced with additional versions and deployments through 2006. The project adapted existing Sony Aibo toy dogs by upgrading them with all-terrain bodies, and environmental-sensing brains and noses. Ready-made 
robotic toy dogs with pre-programmed tasks were identified as having more interesting potential use: these are creatures that so to speak await further instructions. The first generation 'gamma dog' was designed to store and transmit environmental data from any radioactive source that exceeds EPA thresholds. It was anticipated that the deployment of these dogs in multiples could "provide informational spectacle and conclusive on-data convergence in a given local area” (Bureau of Inverse Technology n.d.). During its development, these semi-autonomous gadgets were rerouted to 'sniffer' dog mode by fitting them with environmental sensors capable of detecting environmental pollutants including volatile organic compounds, carbon monoxide and methane, while at the same time providing general indications of air quality.

A number of deployments for the dogs were then arranged at sites likely to be polluted, including a former gas plant at East 173rd Street Works at the Bronx River in New York, where the dogs scouted for volatile organic solvents and polycyclic aromatic hydrocarbons; and at Baldwin Park in Orlando, Florida, where the robot dogs were deployed to search for volatile organic compounds at 'sites of community interest,' including a former landfill site that was a proposed site for a new middle school. This Florida deployment specifically sought to:

provide an opportunity for evidence driven discussion of the environmental issues facing the community, and the opportunity to coordinate diverse opinions and interpretations of the phenomena at hand. Because the dog's space-filling logic emulates a familiar behavior, i.e. "sniffing something out," anyone can participate and try to make sense of this data in real time without necessarily having the technical or scientific training usually required to interpret data from other sources on the same phenomena. It has the potential to raise the standards of evidence involved, promote diverse valid interpretations involved in complex environmental and political processes. (Jeremijenko n.d.-b)

Environmental data was to be obtained by the dog's movements since they were designed to map pollutants by moving toward them and sniffing them out. This is one way of rendering environmental data more perceptible, and more spectacular, while also changing the possibilities of who can generate and access data, as well as who has the evidence necessary and means for contributing to environmental and political debates. Inevitably, the process of monitoring pollutants here and in the projects discussed below is bound up with available sensors that are able to measure specific gases. Such versions of data-led environmental citizenship become tied to prior 
investments in developing sensors with specific technical capacities, often for industrial or scientific uses.

While discussing this project, the group of artists and technologists that came together to work on the project suggested that robotics, environmental sensing, and mapping could propel activism in new ways to different types of engagements, where both gathering data and creative exploration with environmental monitoring might generate renewed engagements with local environments (Lane et al. 2006). Here is a sensing project that is speculating about the possibility for participatory and even citizen-based data collection that intends to create what Benjamin Bratton and Natalie Jeremijenko have elsewhere called "shorter circuits" between environmental information and the observers of that information (Bratton and Jeremijenko 2008). With the collection of environmental data, it is expected that a more immediate and accountable mode of environmental action may also be possible.

Yet, this direct connection between data and action is not necessarily automatic, and in many ways draws on a presupposed efficacy that scientific data are assumed to have in the world. The ways in which climate change data, for instance, fails to have an immediate effect on political action may give rise to speculation about whether data necessarily constitute incontrovertible evidence which can be used to inform and change environmental politics. The failure of data to lead to environmental action may, on one level, have to do with the assumed force of a scientifically evidenced and 'rational' argument, where decisions made in relation to environmental matters of concern are suffused with competing political interests. Yet, on another level, the ways in which data in and of themselves are meant to be-and yet may also fail to be-compelling may raise questions about the affective registers of data. Is a robotic dog a more affective and effective data-creature than a spreadsheet or bar chart? The point here is not to set up a false dichotomy between these data forms, but rather to ask about the ways in which the creaturing and materializing of data may be one way to experiment with the modes and practices of environmental citizenship. In these creaturely arrangements of dogs, pigeons, and eggs, new distributions of participation environmental data and political action may even emerge, but the ways in which this participation informs environmental debate remains an open question that continues to be explored and taken up in subsequent environmental and citizen-sensing projects. 


\section{Pigeons}

If the Feral Robotic Dogs project deployed air-sensing technologies through a robotic toy to make new technical modalities of environmental monitoring more widely available, the Pigeon Blog project raises the question of how air quality sensing shifts even further when pigeons are the reporters and carriers of sensing equipment. Pigeon Blog, developed by Beatriz da Costa with Cina Hazegh and Kevin Ponto in 2006, is a project that used sensor backpacks fitted to homing pigeons to collect low-attitude air quality readings while the pigeons flew through the frequently polluted skies of Southern California. The sensor backpacks consisted of a combined GPS receiver that provided latitude, longitude, and altitude readings, a dual automotive carbon monoxide and nitrogen oxide sensor, a temperature sensor, and a purpose-built mobile phone for transmitting text messages. The backpack kit was developed as a miniature unit small enough to be carried by the pigeons, so that real-time air quality data could be transmitted and visualized as pollution levels on the Pigeon Blog and within a Google Map visualization (da Costa 2006, 2008).

Situated in Southern California and initially developed in Los Angeles, the project addressed the ongoing problem of air pollution and environmental justice by developing an open-source sensing kit that could be used for "grassroots scientific data gathering" (da Costa 2006). The Pigeon Blog project specifically responded to the limited number of fixed air monitoring stations that are focused on generating long-term average data about air quality, and which may not necessarily be located in areas of the highest pollution episodes. By increasing the number of local measurements and data about local exposures, the Pigeon Blog project sought to complement, if not challenge, existing data on air pollution by looking at the distribution of pollution at a finer and more inhabited level. This approach was shared with Area's Immediate Reading, or A.I.R., a 2006 Preemptive Media project (briefly mentioned in the introduction to this chapter), in which da Costa collaborated along with Brooke Singer and Jamie Schulte. Consisting of portable air monitors, A.I.R. enabled urban dwellers to complement coarser and fixed air-quality data by collecting local data through individual journeys (Preemptive Media 2006). Equipped with GPS and coordinated to a database of known pollution sources, the air monitor senses carbon monoxide (CO), Nitrogen Oxides (NOx), and ground level Ozone $\left(\mathrm{O}_{3}\right)$ at distinct locations, and provides real-time visualizations of air pollution levels in relation to an (EPA) air quality index. By making individual maps of urban air pollution exposure, urban dwellers could become more aware and engaged in 
discussing environmental issues through everyday exposure, individual risk, and neighborhood-level mapping.

In both Pigeon Blog and A.I.R., citizen sensing is presented as an activist project of sorts, yet this is not the usual approach to environmental politics that most often develops in relation to issues such as urban air quality. By specifically enrolling pigeons into the project of sensing air, the Pigeon Blog project questions how to develop a mode of "interspecies co-production in the pursuit of resistant action" (da Costa 2008, 377). The pigeons were sent out as 'reporters' to draw attention to the issue of air pollution, while at the same time providing inventive and more accessible ways of gathering data in order to provoke new possibilities of political action. Pigeons participated in this project in multiple ways. Pigeons are not only creatures with particular navigational abilities that often fly according to major landscape features such as highways, but they are also a pervasive bird (if often reviled) in urban areas. Moreover, most pigeons have a close proximity to polluted urban areas, and may provide a specific view of low-altitude air pollution in areas of high traffic. Further, pigeons can act as biosensors making distinct urban experiences available through proxy modes of sensing so we can obtain more insight into our environment.

Pigeons can also be seen to be key contributors to creaturing data and environmental participation in ways that move beyond the usual space of environmental activism. Da Costa makes the point that projects such as Pigeon Blog generate new capacities for engaging with environmental information and for mobilizing participation that are not exclusively focused on "how bad things are" $(2008,379)$. While the project initially set out to provide alternative datasets that might be more widely gathered to add to the expert approaches to environmental monitoring, in many ways this objective was not achieved. Long-term or even complementary datasets were not generated from the project, and this anticipated outcome even became somewhat incompatible with the project's attempt to experiment with new modes of environmental practice and participation. Instead, the most enduring contribution made by Pigeon Blog was its method of experimenting with urban, technological, and more-than-human entities that were to become part of the project of sensing, experiencing, and reporting on air quality. It may be that, while this approach began with a focus on data about air quality, it arrives with a wider approach to environmental practice that is less exclusively data-driven, and is more attentive to the expanded, even ecological, modalities of citizenship that might emerge with such a distributed approach to sensing environments (Braidotti 2006; Gabrys 2012). 


\section{Eggs}

As early experiments into environmental sensing, Feral Robotic Dogs and Pigeon Blog test ways in which new and distributed modes of participation among human and more-than-human modalities can shift the possibilities for political engagement in air quality. These projects continue to inform current citizen-sensing projects, which have only proliferated in the past few years because of the increasing availability and affordability of sensor technologies. Air Quality Egg is another project in this area that seeks to connect maker communities developing digital devices that will enable citizen sensing of air quality (Wicked Device n.d.). Developed as a 'community-led' project, where the community is largely comprised of creative technologists located in New York, London, and Amsterdam, the egg project consists of a Nanode sensing platform that detects carbon monoxide and nitrogen dioxide that the project participants identify as key air pollutants. The air-sensing apparatus is housed in a rapid-prototyped egg-shaped shell that was first tested at the second Citizen Cyberscience Summit in London in 2012. The project has subsequently earned considerable backing on Kickstarter. The project website indicates that the eggs are primarily located in the United States, Europe, Australia, and Japan, and gather various measurements that are uploaded to a Xively data platform.

While the Air Quality Egg project is ostensibly focused on air quality monitoring, its origin stems from technical communities that are highly motivated to experiment with the kit of sensing devices, or to engage in what has been referred to as 'participatory sensing' experiments by bringing the functionalities of sensors to more explicit points of encounter (DiSalvo et al. 2012). At the same time, there are many questions that arise as to how these devices perform, and the extent to which the data they generate are accurate. Concerns about the Air Quality Egg project have led to a heated debate about how viable it is to monitor air quality accurately given the scale and coarse instrumentation of these technologies, and whether the sensors were even accurately calibrated. To what extent are egg-gathered data useful and accurate? And what if the egg fails to even function in the first place (as was the case in several of the prototyping workshops)?

In a project video, however, commentators on the project suggest that accuracy of data was not the primary concern, since sense data may provoke environmental concerns that could always be followed up with more thoroughly scientific studies. Here, they argue, the focus was on the community of egg users and developers inclined toward testing devices that may create further calls to action, even if the links between the local, sporadic, and 
somewhat momentary datasets and informing environmental science, policy, and behavior were not always clear. At one point in the project video, which captured the testing of the egg during the London Cyberscience event in spring 2012, a participant remarked, "the chicken is not ready," referring to the back-and-forth attempts to have the egg set-up, calibrated and ready to gather measurements.

In the context of creaturely data, this project seems to be an entity in formation where a sensor-led technical kit is the egg-like impetus for galvanizing and drawing together environmental issues and action. The environments that emerge here are highly informed by computational modes of sensing and acting. Data gathered through electronic sensing is seen to be the force that propels perceived possibilities for activism, but here the force of data depends less on the accuracy of data and more on the process of making a device that can draw attention to data practices as materialized and potentially political engagements. Data is creatured in the Air Quality Egg as a data-generating device ready to hatch and give rise to new modalities of data-driven activism. Yet, it can be argued that the modes of participating in making devices and generating data are very different entities and occasions than modes of participating in environmental activism, which in the case of the egg may be a legitimating subtext, but which is not the primary focus in this tech-led approach to participation.

\section{Conclusion: Experimenting with environmental citizenship}

The three projects discussed here share a similar approach to environmental sensing by pursuing more democratic engagements of data gathering in order to inform environmental politics. Yet beyond these similarities, very different entities and modalities of citizenship come together in these projects. The Feral Robotic Dogs project tests specific deployments in landfills and the proposed site of a new middle school, making the point that from these specific sites, new communities of interest might emerge to influence environmental debate. Dealing with data is rendered as a more haptic and materialized experience, something demonstrated through a fleet of sniffing robotic dogs. The Pigeon Blog seeks to make urban air quality visible through a more-than-human engagement, which at once redistributes environmental participation while adopting a more experimental approach to sensing urban environments. And the Air Quality Egg focuses on developing an Internet of Things approach to creating a worldwide sensor network, where new 
devices and the data they generate are seen to lead to new possibilities for participation and the formation of communities.

Yet with each of these projects, the transition from environmental sensing experiment to citizen-based engagement in environmental issues remains unclear. There are multiple issues that emerge with more grassroots modes of environmental monitoring. As the London Air Quality Network points out, monitoring air quality on a DIY-level may not be as easy as it first appears due to the expense of precisely instrumented sensors, and the questions of accuracy that pertain to sensing projects that use less refined sensing equipment, or that are not set-up in a systematic way to study environments over time. The dogs, pigeons, and eggs of these projects are not gathering data with the required rigor of a scientific study, but they are making a case for the development of complementary data sets that influence what is monitored and how it is brought to our attention in order to be acted upon.

At this level of action, additional questions emerge as to how environmental sense data may inform environmental politics and actions. In an earlier human-computer interaction research project, Common Sense, which tested the deployment of sensors for measuring air quality on street sweepers, the project participants concluded that environmental community organization is actually the most critical factor in order for data generated through sensor deployments to be relevant, meaningful and actionable (Aoki et al. 2008). In some cases, community environmental organizations have been shown to be rather skeptical about the extent in which more data from computational sensors will necessarily facilitate more effective action. In this way, some researchers question whether more localized and data-led processes of environmental observation and monitoring actually do enable greater environmental participation.

While environmental sense data gathered without a clear link to community projects may not have the anticipated a/effects of facilitating greater participation in environmental matters of concern, these projects do experiment with the methods, techniques, communities, modes of participation, sites of monitoring, and evidential modes of activism and politics that might emerge as new entities and processes for engaging with environments and environmental issues. These experiments with affectivity, effectiveness and practice make space - as well as contribute to further controversies - regarding different approaches to environmental politics and participation that might be investigated further. Data as typically conceived may not be the critical unit for mobilizing environmental citizenship and action, and a gadget-led process for engaging with politics may not be the most definitive answer to developing new modes of environmental 
engagement. However, these citizen-sensing projects raise the question of what other experiments might emerge that open up the possibility for new types of environmental politics, and new modes of collective participation (Gabrys and Yusoff 2012). Within this space, the modes and practices of data- the creaturely entities in and through which data manifest and give rise to worlds - are arguably an area yet to be fully explored, since data are so frequently presented as the dematerialized evidence of environmental fact. But the modalities, materialities, and creatures of data may be one way of experimenting with the ways in which monitoring practices might establish new sites of environmental engagement, where affectivity might be one way to reconsider the effectiveness of data.

\section{Acknowledgments}

This chapter is based on a manuscript written in 2013, which since then has also been published (in a revised version) as 'Sensing air and creaturing data' in Program earth: Environmental sensing technology and the making of a computational planet (Gabrys 2016, 157-181). The research leading to these results has received funding from the European Research Council under the European Union's Seventh Framework Programme (FP/2007-2013) / ERC Grant Agreement n. 313347, Citizen sensing and environmental practice: Assessing participatory engagements with environments through sensor technologies.

\section{References}

Aoki, P. M., R. J. Honicky, A. Mainwaring, C. Myers, E. Paulos, S. Subramanian, and A. Woodruff. 2008. Common sense: Mobile environmental sensing platforms to support community action and citizen science (demonstration). In Proceedings of the 1oth international conference on ubiquitous computing (adjunct programs), Seoul, September 21-24, 2008, 59-6o. http:// www.ubicomp.org/ubicomp2oo8/ubicompo8adjunct.pdf.

Bickerstaff, K., and G. Walker. 2003. The place(s) of matter: Matter out of place - Public understandings of air pollution. Progress in Human Geography 27 (1): 45-67.

Bowker, G. 2005. Memory practices in the sciences. Cambridge, MA: The MIT Press.

Braidotti, R. 2006. Transpositions: On nomadic ethics. Malden, MA: Polity Press. 
Bratton, B., and N. Jeremijenko. 2008. Suspicious images, latent interfaces. Situated Technologies Pamphlets 3. New York: The Architectural League of New York.

Bureau of Inverse Technology. n.d. Feral robotic dog development squad 1.1 codename sniffer. BIT. http://www.bureauit.org/feral.

Burke, J., D. Estrin, M. Hansen, A. Parker, N. Ramanathan, S. Reddy, and M. B. Srivastava. 2006. Participatory sensing. In Proceedings of ACM Sensys World Sensor Web Workshop, Boulder, CO, October 31, 2006. New York: ACM. da Costa, B. 2006. Pigeonblog 2006-08. Beatriz da Costa's Blog and Project Hub. http://web.archive.org/web/20130527223456/http://beatrizdacosta. net:80/Pigeonblog

- 2008. Reaching the limits. In Tactical biopolitics: Art, activism, and technoscience, eds. B. da Costa, and K. Philip, 365-385. Cambridge, MA: The MIT Press.

DiSalvo, C., M. Louw, D. Holstius, I. Nourbakhsh, and A. Akin. 2012. Towards a public rhetoric through participatory design: Critical engagements and creative expression in the Neighborhood Networks Project. Design Issues 28 (3): 48-61.

Ellis, R., and C. Waterton. 2004. Environmental citizenship in the making: The participation of volunteer naturalists in UK biological recording and biodiversity policy. Science and Public Policy 31 (2): 95-101.

Gabrys, J. 2012. Sensing an experimental forest: Processing environments and distributing relations. Computational Culture 2. http://computationalculture.net/article/sensing-an-experimental-forest-processingenvironments-and-distributing-relations.

-. 2013. Ecological observatories: Fluctuating sites and sensing subjects. In Field_Notes: Field and laboratory as sites for art \& science practices, eds. L. Beloff, E. Berger, and T. Haapoja, 178-187. Helsinki: Finnish Society of Bioart.

-. 2016. Program earth: Environmental sensing technology and the making of a computational planet. Minneapolis, MN: University of Minnesota Press.

Gabrys, J., and K. Yusoff. 2012. Arts, sciences and climate change: Practices and politics at the threshold. Science as Culture 21 (1):1-24.

Irwin, A., and M. Michael. 2003. Science, social theory and public knowledge. Maidenhead, UK: Open University Press/McGraw-Hill.

Jasanoff, S. 2003. Technologies of humility: Citizen participation in governing science. Minerva 41:223-244.

Jeremijenko, N. n.d.-a. Environmental Health Clinic. Facebook. http://www. facebook.com/xclinic.

—. n.d.-b. Feral Robotic Dogs. New York University. http://www.nyu.edu/ projects/xdesign/feralrobots. 
Lane, G., C. Brueton, G. Roussos, N. Jeremijenko, G. Papamarkos, D. Diall, D. Airantzis, and K. Martin. 2006. Public authoring \& Feral robotics. Cultural Snapshot 11. http://proboscis.org.uk/publications/SNAPSHOTS_ feralrobots.pdf.

London Air Quality Network. n.d. London air. King's College London. http:// www.londonair.org.uk/LondonAir/Default.aspx.

Ottinger, G. 2010. Buckets of resistance: Standards and the effectiveness of citizen science. Science, Technology \& Human Values 35 (2): 244-270.

Preemptive Media. 2006. AIR: Area's Immediate Reading. Air Preemptive Media Project. http://www.pm-air.net.

Stengers, I. 2008. A constructivist reading of process and reality. Theory, Culture \& Society 25 (4): 91-110.

Whitehead, A. N. 1929. Process and reality: An essay in cosmology. New York: The Free Press.

Whitehead, M. 2009. State science and the skies: Governmentalities of the British atmosphere. Malden, MA: Wiley-Blackwell.

Wicked Device. n.d. Air Quality Egg. Wicked Device. http://www.airqualityegg.com.

Wynne, B. 1996. May the sheep graze safely? A reflexive view of the expert-lay knowledge divide. In Risk, environment and modernity: Towards a newecology, eds. S. Lash, B. Szerszynski, and B. Wynne, 44-83. London: Sage Publications.

\section{About the author}

Jennifer Gabrys is Chair in Media, Culture and Environment in the Department of Sociology at the University of Cambridge, and Visiting Professor in the Department of Sociology at Goldsmiths, University of London. She is principal investigator in Citizen Sense and AirKit, two projects funded by the European Research Council. Her research investigates environments, digital technologies, and citizen participation through theoretical and practice-based work. Her books include a techno-geographical investigation of environmental sensing, Program earth: Environmental sensing technology and the making of a computational planet (University of Minnesota Press 2016); and a material-political analysis of electronic waste, Digital rubbish: A natural history of electronics (University of Michigan Press 2011). Together with Gay Hawkins and Mike Michael, she has co-edited an interdisciplinary collection on plastics, Accumulation: The material politics of plastic (Routledge 2013). Her work can be found at citizensense.net and jennifergabrys.net. 